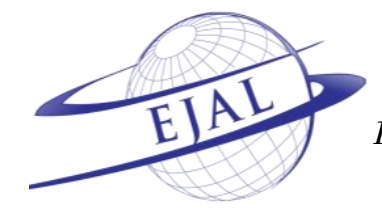

Available online at www.ejal.info

EJAL

Eurasian Journal of Applied

Linguistics

\title{
Online and face-to-face peer review in academic writing: Frequency and preferences
}

\author{
Rashad Ahmed aid, Abdu Al-Kadi b,c *iD \\ a Jacksonville State University, AL, USA \\ ${ }^{b}$ Ibb University, Ibb, Yemen \\ ${ }^{c}$ University of Science \& Technology (UST), Taiz, Yemen
}

\begin{tabular}{l|l|l} 
Received 18 August 2020 & Received in revised form 22 February 2021 & Accepted 08 March 2021
\end{tabular}

APA Citation: Ahmed, R. \& Al-Kadi, A. (2021). Online and face-to-face peer review in academic writing: Frequency \& preferences. Eurasian Journal of Applied Linguistics, 7(1), 169-201.

Doi: http://dx.doi.org/10.32601/ejal.911245

\begin{abstract}
With the current advancement of technology and its potential for better teaching and learning outcomes, this paper compares the use of peer review in face-to-face settings and online platforms. The study recruited 142 students and 20 instructors from an American public mid-southern university. Data were collected over two academic semesters and included three instruments: questionnaires, observations, and interviews. Findings indicated that the participants generally hold a positive stance towards peer evaluation. They found face-to-face peer assessment during writing class time to be the most common and effective mode for they preferred immediate feedback in person. Contrary to laudable prior research findings, the majority of participants considered online review ineffective. They found various forms of technology quite distracting. Analyzing the extent to which native English speakers, non-native speakers, and instructors find virtual and face-to-face types of review worthwhile makes the study a valuable factor for instructors who wish to incorporate peer editing into their teaching.
\end{abstract}

(C) 2021 EJAL \& the Authors. Published by Eurasian Journal of Applied Linguistics (EJAL). This is an open-access article distributed under the terms and conditions of the Creative Commons Attribution license (CC BY-NC-ND) (http://creativecommons.org/licenses/by-nc-nd/4.0/).

Keywords: Academic writing; feedback; peer review; writing instruction

\section{Introduction}

Digital technology has streamlined teaching and learning. It affords instructors and learners opportunities for language enhancement online and offline. Besides classroom interaction, they can meet and interact through numerous electronic applications and platforms. Insofar as writing is concerned, technology is increasingly incorporated with peer-to-peer reviews (Ahmed, 2020; Moloudi, 2011; Saeed, Ghazali, \& Aljaberi, 2018). In class and in online composition, the peer review (hereafter PR), also known as peer assessment, peer editing, or peer evaluation has become a vivid activity. It is invaluable

\footnotetext{
${ }^{*}$ Corresponding author: Abdu Al-kadi. E-mail address: findtalib@gmail.com http://dx.doi.org/10.32601/ejal.911245
} 
for students as it helps them organize their papers better, beef up their abilities in revision strategies (Berg, 1999; Hojeij \& Baroudi, 2018; López-Pellisa et al., 2020), and discover their strengths and weaknesses (Hu, 2005). Brammer and Rees (2007) opined that "having students critique each other's papers has become commonplace in the composition classroom and in English composition textbooks" (p. 71). PR has been reported to "facilitate the critique through shared greetings that personalize the activity and establish goodwill and camaraderie in a difficult task" (Mick \& Middlebrook, 2015, p.144). Incorporating PR in writing classes, especially in L2 contexts, accelerates the revision and editing process (Moloudi, 2011). Caulk (1994) examined the effectiveness of $\mathrm{PR}$ in academic writing and found that 89 percent of the participants made useful comments and sixty percent came up with good suggestions.

With the current widespread use of technology in language education, the question arises on how technological tools augment the process of PR. Although several researchers have undertaken the topic from several viewpoints, comparing technologyenriched review to in-class PR is a rarity (Hoomanfard \& Rahimi, 2018; Huang, 2016; Li \& Li, 2018; Moloudi, 2011; Razi, 2016). Comparing the perceptions of both students and instructors is also a rare undertaking. Additionally, some researchers identified problems of PR but did not discuss solutions sufficiently (e.g., Ho, 2015; Huang, 2016; Moloudi, 2011). This gave an impetus for the current study to extend evidence on the topic. More pointedly, this paper pores over writing instructors and students' experiences in online and face-to-face $(\mathrm{F} 2 \mathrm{~F})$ peer evaluation. The overriding goal was to inspect whether technology has an effect on the process of $\mathrm{PR}$ in academic writing classes. The following questions were used to chart the territories of the investigation:

1. Which types of peer review do first-year college students commonly use in their academic writing, online peer review or in-person peer review?

2. Which of these two types of peer review do students and their instructors perceive as more effective?

The enquiry appeals to the interests of instructors not only in academic writing classes but also in any subject area in which writing plays a significant role, as the paper discusses pedagogical implications for educators and students (native and nonnative speakers of English) - referred to as NS and NNS. The findings are also significant for theorists and practitioners in rhetoric and composition and computers and writing studies.

\section{Literature Review}

The use of peer assessment in writing instruction takes its theoretical underpinning from the collaborative learning theory (Hansen \& Liu, 2005), activity theory (Lei, 2008; Lin \& Yang, 2011), and Vygotsky's Zone of Proximal Development (ZPD). These frameworks conceptualize learning as a social activity. Studies conducted on L2 learners affirm that learners who work collaboratively develop grammatical accuracy, vocabulary, and discourse (DiCamilla \& Anton, 1997; Storch, 2005). This collaboration manifests itself in academic writing as it affords students chances to read 
others' writing, give or receive feedback on their writing (Hoomanfard \& Rahimi, 2018; López-Pellisa et al., 2020). Arguably, such interaction among peers during the process of PR bolsters students' confidence and willingness to revise others' work and discuss problematic issues (Chen, 2012).

\subsection{Peer Review in Bilingual Contexts}

Academic writing classes in the US consist of NS students or L1 and NNS students or L2. NNS learners come from different cultural, social, and linguistic background. This diverse environment requires teachers to adjust their teaching methods in order to match the needs of all students. This includes bringing students of different orientations together to partake in shared activities (peer reviewing is a case in point). Coordinating PR in classes comprised of mixed L1 and L2 learners, Zhu (2001) conducted a study on three groups with each group consisting of NS and NNS. The study analyzed students' PR comments to explore differences in their written feedback due to variations in their linguistic backgrounds. The findings revealed that NNS learners contributed less than their L1 counterparts did. Even though their participation was low, their written feedback was similar to that of their NS classmates. Similarly, Crossman and Kite (2012) examined the use of PR among NS and NNS. The study was conducted on 208 students representing 60 countries; 138 were NNS and 70 NS. They were to choose another student and complete the PR with them. The study reported significant improvement from the first to the final draft. Specifically, this development was observed in the aspects of organization, support, audience focus, and writing conventions. Overall, the study found that face-to-face PR helped L1 and L2 students develop the quality of their writing.

More evidence obtained from case studies reinforces the aforementioned findings. For instance, Cheng (2013) investigated the nature and types of collaboration and interaction between NS and NNS of English. The researcher conducted a case study on a NNS from Korea and her native classmates, who were working collaboratively with her on a writing project for two semesters. The findings revealed that there were power issues with NS assuming themselves as more authoritative than NNS. This dynamic helped the NNS develop personal coping strategies, which positively affected the outcome of the writing project. Another case study undertaken by Bradley (2014) examined students' interactions and reflections in an intercultural wiki environment in which NNS students interacted with NS to communicatively refine texts in terms of linguistic and intercultural aspects. Two groups of learners coming from a range of countries with different linguistic backgrounds, different disciplines and locations met over the web, exchanged content, and provided comments on written texts. The results showed a great variation in the comments provided by the peer reviewers and thus increased chances of intercultural thought exchanges. 


\subsection{Online Vs. Face-to-face Peer Review}

Researchers have delved into different modes of PR to determine practices that are more effective than others. Relying on evidence in the literature, online and face-to-face PR have pros and cons. Online PR has been the leitmotif of several investigations. Breuch (2004) compared both online to F2F peer evaluation, arguing that the former enables students to archive and categorize written comments of reviewers for future reference as they revise their work. It also makes such comments available for instructors to review. Breuch opined that these advantages barely exist in F2F review environments. In Breuch's words, "students may not remember all comments that students offer, and instructors seldom have the opportunity to examine comments offered by peer reviewers" (p.52). Likewise, Huang (2016) investigated the efficacy of online PR among EFL learners and concluded with a positive note of its effectiveness as it increased students' interests and performance. In a similar vein, Vorobel and Kim (2017) examined students' practices in F2F vs. online PR, using different methods including interviews, e-journals, artifacts, and observations. The participants were four high school students in the United States who reported their preference of online PR over F2F review for they found it more convenient. Moreover, Daweli (2018) explored PR in the Saudi EFL context, employing Google Docs as a tool to engage learners online. The study explicated whether collaborative editing of their peers' texts using Google Docs improve leaners' writing. The findings showed positive attitudes toward this type of PR. This suggests that students' beliefs, experiences, and hierarchical power in the classroom affect their feedback.

In a more elaborated study, Saeed, Ghazali, and Aljaberi (2018) traced the development of relevant research in L2 writing from 1990 to 2016. The author reviewed 37 studies on feedback exchange in $\mathrm{F} 2 \mathrm{~F}$ and online PR. The study looked into the modes of review and the issues that limited interactional feedback exchanges. It provided salient implications for the dual space-interactional feedback model that comprises the learning space and the social space of interactional feedback in PR. According to the authors, L2 students created more global comments when doing PR online. They added that in order to increase the effectiveness of online PR, the discussions had to be scheduled at a specific time.

Scrutinizing PR through online tools such as wikis, blogs, and Turnitin is evident in the literature. Concerning wikis as platforms for PR, Lin and Yang (2011) considered integrating wikis into a course of English writing. The participants positively viewed wiki-based review, a finding endorsed by Desirable (2015) who argued for wikis as a helpful tool for developing students' critical thinking skills while reviewing peers' work. In a similar landscape of research, Chen (2012) discussed peer reviewing in EFL writing classrooms based on blogs in the Chinese context. Chen employed 67 undergraduate students, who used blogs in an academic writing class. PR was an integral part of the course. Instead of completing written tasks, the participants were encouraged to exchange feedback/opinions on composition. The findings showed positive reflective responses on an end-semester survey. The advantages of weblog PR included relieving 
stress, increasing self-confidence, convenience, and accessibility. In a relevant context, $\mathrm{Li}$ and $\mathrm{Li}$ (2018) underscored common challenges of PR, providing some suggestions to make it more profound. The authors suggested using a new platform called Turnitin for PR activities in an ESL academic writing for it helps in turning the reviewers' attention from local to international issues such as plagiarism. It also enables them to elaborate on their comments by using pop-up boxes or online comments.

Although substantial research found online PR more helpful than F2F PR, other studies went the other way round. For instance, Ho (2015) studied the influence of online PR on students' revised drafts. The findings showed that F2F discussions were more effective than online feedback because students got immediate feedback in-person and were able to get some clues through body language and facial expressions. Similarly, Liu and Sadler (2003) inspected how the two modes of PR (online and faceto-face) affect the types and nature of students' comments. The study was conducted on 48 students at a US university. The first class consisted of L2 learners only and was tasked to follow the traditional method. The second class consisted of seven L1 and 17 second language learners. They were asked to use technology in their PR. Both groups, taught by the same teacher, were given identical assignments. The results revealed that face-to-face PR was better for communication whereas online PR produced more comments. The researchers suggested that both modes help students improve their writing.

\subsection{Salient Drawbacks}

Even though PR is commonly used in writing classes and possesses the potential for great pedagogical implications, there are conundrums that impact its implementation and effectiveness. The challenges include, but are not limited to, instructors' preparation or understanding of effective employment of PR or being aware of the potential problems. Indeed, technology can be distracting to some learners (Kessler \& Bikowski, 2010; Ho, 2015) and some instructors feel overwhelmed to learn about all of these different tools to help them achieve their teaching goals (Kessler, 2018; LópezPellisa et al., 2020). Additionally, in-class PR as in online, students may not meet the expectations of their instructors (Kessler \& Bukowski, 2010). Moreover, lack of motivation to perform PR limit its merits. Hojeij and Baroudi (2018) studied the effects of a 10-week training on motivation and engagement in PR as a method of improving the quality of feedback on EFL writing. This training was F2F and self-paced through mobile technology learning apps. The results showed that juxtaposing peer editing training, F2F and mobile learning tools positively influenced EFL students' revisions and overall writing.

Kaufman and Schunn (2011) identified key detriments that affect students' negative perception towards PR. The authors used an online platform called "SWoRD" and distributed a survey to 250 students from six universities. First, they examined the perceptions of the participants who received feedback from their instructors and peers. Second, they singled out a sub-sample ( $\mathrm{n}=84$ students) who received feedback from their 
peers only to investigate their perceptions. The findings of the first group yielded positive results where students appreciated getting feedback from their teachers and peers. For the second group, participants considered PR unfair and they claim that they did not have confidence in their peers giving them feedback because they did not have the requisite knowledge to do so. However, their perceptions changed to be more positive when the researchers made them practice PR as opposed to merely anticipating the activity. Likewise, Roskams (1999) examined how cultural beliefs influence the attitudes of peer reviewers. In the study 200 EFL students at a Hong Kong university were tasked to work in pairs. The data was collected via pre/post questionnaires designed to elicit information about students' attitudes about working together. The study show that student were more anxious before the PR, but their perceptions changed towards the end of the semester. The participants generally believed that PR helped them share the workload and make new friends. They generally found PR to be more productive than working individually.

For these reasons, Razi (2016) cautioned lecturers to avoid heavy reliance on PR as a sole way of enhancing academic writing. This is in part because feedback provided by reviewers whose L2 expertise is limited might result in poor review outcomes and distrust of this type of evaluation.

Pulling previous studies together, it is evident that PR continues to be essential for academic writing. Despite a plethora of previous studies on the topic, some issues have not been well- researched. Topics such as students' preferences of a specific PR mode remains open for further debate. What is more, online platforms make the review process easier and faster, yet students and their teachers' taste vary from context to another. Most of the relevant studies capitalized on the students' perspectives on PR, and only a few touched on teachers' perspectives and practices (Vorobel \& Vásquez, 2014) or compared the perceptions of both students and instructors (Hoomanfard \& Rahimi, 2018). As explained above, prior research expounded peer review either in L2 contexts or on graduate students. The undergraduate mixed classes, specifically the first-year writing classes have been under-researched. Thus, this study builds on previous research findings and revisits the technique of peer evaluation with two modes of review in mind: the traditional $(\mathrm{F} 2 \mathrm{~F})$ versus technology-based (online) PR at the undergraduate level in a monolingual/bilingual context. It is primarily concerned with the experiences of students and instructors, the rate at which they use online and F2F peer feedback, and how they perceive the usefulness of each modality.

\section{Method}

\subsection{Context and Design}

The study at hand is part of a larger mixed-method investigation conducted in a midsouth public university that requires first-year students to enroll in academic writing classes with an aim to boost students' academic writing skills. Each class meets twice a week for 90 minutes every session. In these classes, students work on different writing projects and perform PR for all the major assignments. Students of all majors are 
required to take at least one academic writing class. The selection of this institution made it possible for the researchers to target L1 and L2 students with different educational background. Many of the students joining this university are firstgeneration attendants. They come from different parts of the US and the rest of the world. The mixed-method approach was employed by triangulating trends from quantitative and qualitative data. The former was deemed appropriate to examine both students and their instructors' perceptions on various aspects of PR and to ascertain significant differences between students and teachers' perspectives, if any. The latter supplemented the quantitative data for a more in-depth understanding of certain answers.

\subsection{Participants}

The participants were 142 undergraduates and 20 of their instructors, and they were recruited on a voluntary basis. The student sample included 124 NS and 18 NNS. The NNS students had different linguistic background: Spanish, Arabic, Chinese, Amharic, Susu, and Vietnamese. They were 47\% male and 53\% female. The study employed both NS and NNS to vindicate whether the variable of 'nativity' plays a crucial factor in the overall stand of PR. Teacher sampling consisted of full-time instructors and teaching assistants. Ninety percent of them were NS of English and only ten percent were NNS teaching assistants (60\% females vs. $40 \%$ males).

\subsection{Instruments}

Data were elicited from the participants in three phases through questionnaires, interviews, and observations - a practice referred to as a 'methodological triangulation,' defined by Brown \& Rodgers (2002) as an "attempt to understand some aspects of human behavior by studying it from more than one standpoint, often making use of both quantitative and qualitative data in doing so" (p. 243). This triangulation (Figure 1) included a questionnaire for students and another for instructors. The former consisted of 22 questions and the latter 22 questions, including yes-no, multiple-choice, and Likert-scale questions. To prevent ambiguity, the questionnaires were piloted on a small group of participants with similar characteristics. They were also evaluated by a committee of five specialists in the field of Applied Linguistics whose feedback and input were taken into consideration to prepare the fine-tuned drafts. Each of the questionnaires was designed with a certain focus. The instructor's version focused on the frequency, types and purpose of incorporating PR in their academic writing classes. The students' version, on the other hand, elicited information on how often their teachers asked them to participate in peer editing, types and formats they used for that purpose, and whether they prefer structured or unstructured PR and why.

Observations and interviews followed up the survey implementation to strengthen evidence by collecting more hunches relevant to the inquiry. First, four writing instructors were observed during ongoing classes. Each meeting lasted for 90 minutes. 
Then they were interviewed to further investigate their employment of PR. The interviews were of the semi-structured type in which some questions were adapted from Vorobel and Vásquez (2014) with their permission. The interviews elicited information about the reasons behind uses of certain strategies in writing classes, and why teachers preferred to use specific modes of PR to others.

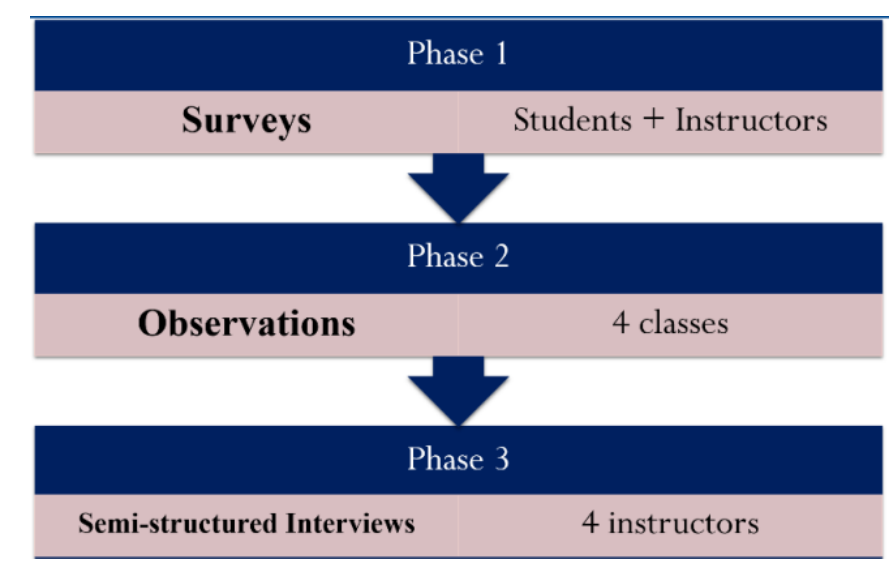

Figure 1. A Flowchart of the phases of data collection

\subsection{Procedures}

To obtain answers to the research questions, quantitative and qualitative data were collected as illustrated in Figure1. The process of data collection extended for approximately eight months over two academic semesters. Upon the department's permission to contact all the academic writing instructors and their students, the researchers sent individual invitation emails inviting subjects to partake in an online opinion poll. The instructors were also encouraged to send a different email to their students. The response rate was $56.5 \%$ for the students (142 students out of 250 ) and $40 \%$ for the instructors (20 out of 50). Participation was voluntary and all the participants were allowed to withdraw at any time if they wished to do so. Following the surveys, four instructors were selected (based on their experiences) for observations and interviews: two experienced full-time instructors and two teaching assistants who had been teaching for a relatively short period. The notes taken from observations were analyzed along with the other types of qualitative and quantitative data as illustrated in the results section.

\subsection{Data Analysis}

Two types of data were treated: quantitative and qualitative data. Both were crosschecked and discussed. The survey questions were marked as required and none of the responses were missing. The process of quantitative data analysis started with feeding the Statistical Package for Social Science (SPSS 21.0) with the informants' responses in forms of codes. All the items in the survey were embarked coded, except 
for extensive texts obtained by open-ended questions, which were analyzed qualitatively. Each predetermined scaled option was assigned a number (code). With all the quantitative data, descriptive and inferential statistics were obtained, classified, and transformed into numerical values arranged in tables and figures. The descriptive statistics (mean, SD, 95\% confidence interval), frequency tables and percentages, and inferential statistics for comparing the three groups of participants on their responses to the different items on the survey. Considering the presence of skewed distributions, frequency data, and unequal number of participants in the groups, the data were analyzed through the non-parametric Kruskal-Wallis test for k-independent samples, which is recommended in such cases (e.g. Field, 2009). Following this analysis, post hoc tests were performed to determine whether significant differences existed between the groups.

On the other hand, the qualitative data, obtained through open-ended question in the survey, observations and interviews were analyzed subjectively. They underwent the procedures of data reduction resulting in groups of categories, labeled by specific names. Students and teachers' comments were compared to extract trends and to identify similarities and differences. Mutual features were clustered into themes. The participants' responses were grouped according to different themes with sample quotes. Each theme was supported by a specific percentage of participants included with the analysis. The data collected from the observations and interviews enriched the analysis. Since there were only four interviewees, all of the responses were presented while trying to compare the experienced and the inexperienced teachers. The process of data analysis is presented visually in Figure 2.

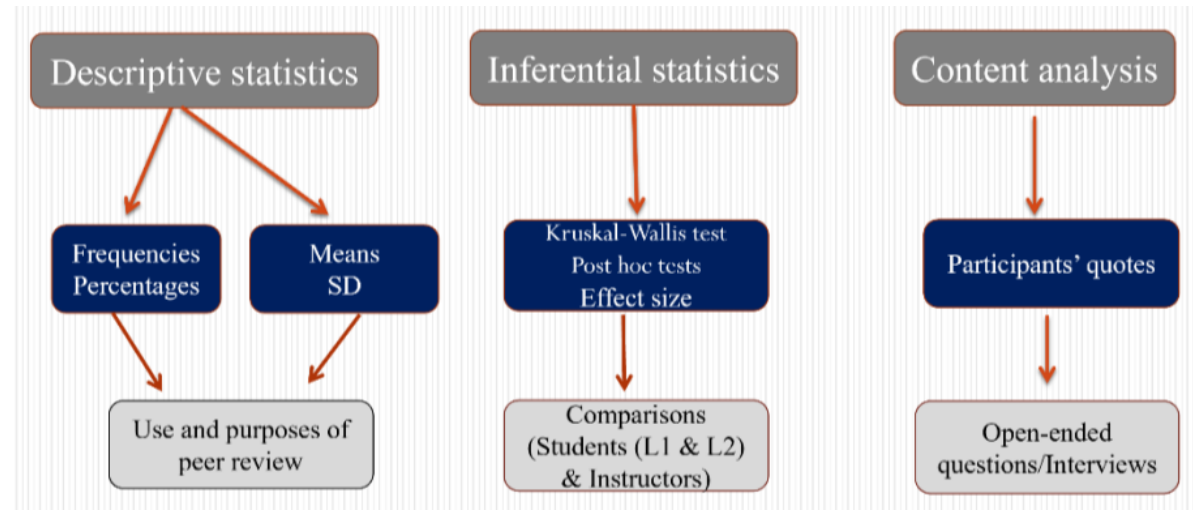

Figure 2. The analysis framework

\section{Results \& Discussions}

This study is an attempt to find the commonly used types of PR among college students. It specifically compared online PR to the F2F mode employing a statistical analysis to explicate significant differences in the way teachers and students perceive and practice peer evaluation. 


\subsection{Types of PR in Academic Writing}

The first research question aimed to elicit data regarding five types of PR used in academic writing classes: (a) face-to-face during class; (b) paper-based during class; (c) online during class; (d) online as homework; (e) not used at all, and other. Relevant data in students' questionnaires and teachers' interviews were used to answer this enquiry. Based on the percentages of participants who checked the options, data in Figure 3 illustrates that $F 2 F$ peer review during class time was the most frequently used type of $\mathrm{PR}$, followed by paper-based written peer review during class time. Following these two types is the use of online PR during class time and lastly online PR as homework. The results show that online $\mathrm{PR}$ is not as common as in-class or paper-based PR. Only three students (2\%), all of whom are NSs, reported that they did not use PR because they found it ineffective. Here are quotes of their answers to the open-ended questions in the survey: "I don't use them because I don't find it helpful/effective. The people that do the review don't really give good feedback to you so I don't use them." One NS student chose the option 'other' and reported that he prefers instructor's feedback because of grading: "I personally don't enjoy peer reviews. I only like my reviews to come from the teacher. They are the ones grading, so their opinion is the only one that matters." The results in the figure are in line with the results in Table 1 where online peer editing ranked smaller than in-class PR.

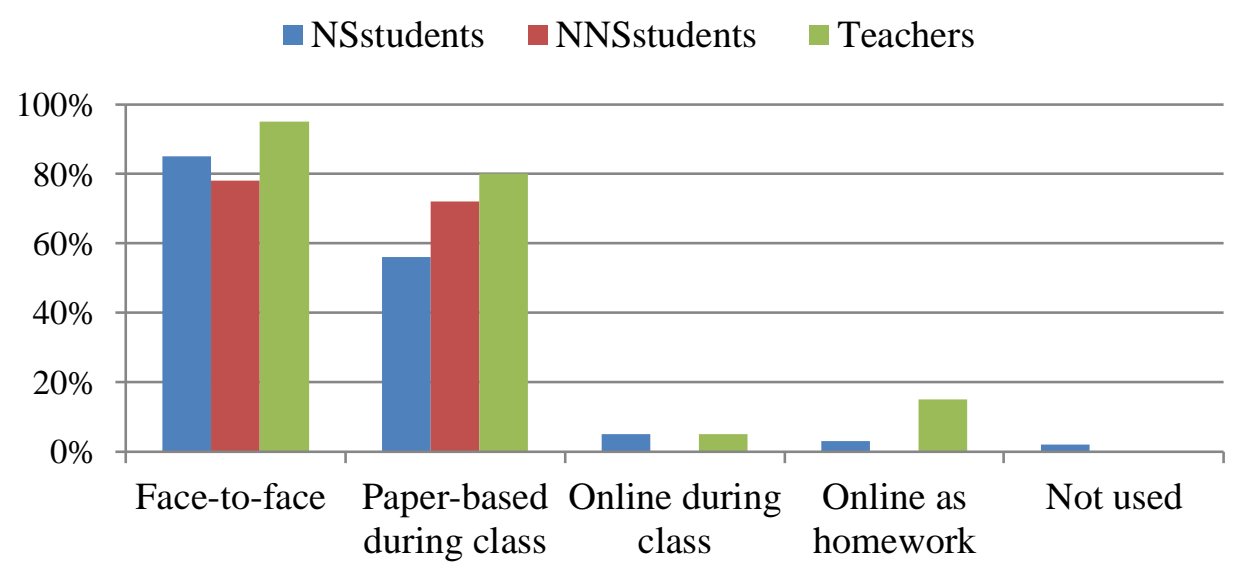

Figure 3. Types of PR ordered from the most to the least commonly-used types

Excluding the last option, "other", Kruskal-Wallis tests were used to check for significant differences between groups. Table 1 outlines the results of the descriptive statistics. As the table displays, only one significant (between-group) difference on the use of online peer review assigned as homework, Chi-square $=6,648, p=.036$. The effect size of this difference is low (.041) according to Cohen's reference values. The rest of the options show a lack of significant differences between the groups with p-values $>.05$ and very small effect size values. Based on the results of Kruskal-Wallis, post hoc pairwise comparisons (Table 2) were performed only for online PR assigned as homework. 
The alpha level was adjusted to .0166 (.05/3) since three pairs of comparisons were involved. Lack of significant differences between the groups shows an agreement among the participants about the most commonly used modes of PR. In this particular case, it attests as well to the reliability and truthfulness of the responses because in view of the fact that all of the participants belong to the same academic unit and share the same or similar experiences. According to the adjusted level of significance, none of the pairwise comparisons is significant at the corrected alpha level: NS students- NNS students, $p=.441 ; \mathrm{NS}$ students-teachers, $p=.024>.0166$; NNS students - teachers, $p=.059$. However, there are still descriptive differences, showing that the highest percentage in the teacher's group (15\%).

Taken together, the dataset in Figure 3, Tables 1 and 2 suggest that both students and teachers believe that F2F peer assessment during class time was the most commonly used type of PR. This may suggest that F2F peer assessment is more preferable than online $\mathrm{PR}$, at least to the participants in question. On the other hand, researchers (e.g. Huang, 2016; Lin, \& Yang, 2011; Vorobel \& Kim, 2017) investigated this issue and found that online PR is more effective. Huang (2016) found that online $\mathrm{PR}$ is helpful for EFL learners because it makes learning engaging, however, teachers should monitor and guide students throughout the whole process. Other similar studies (e.g. Lin \& Yang, 2011) found that online tools like wikis have the potential to be effective for PR sessions. A comparison study by Vorobel and Kim (2017) investigated the use of PR from the perspectives of four high school students in the US, and the study reported that students prefer online PR to other forms. The findings of the current study, however, diverged these results. It shows that F2F peer assessment was more common (Figure 3) and more effective (Figure 4) than online PR.

Perhaps, this is because the current study scrutinized the frequency that students 'used' the feedback, whereas other studies looked into its effectiveness. Effectiveness could be interpreted as enhancing the current manuscript through revising and rewriting or improving a subsequent new writing. Therefore, the results are not necessarily comparable. Additionally, previous studies (e.g. Breuch, 2004; Hoomanfard \& Rahimi, 2018; Huang, 2016) examined the effectiveness by comparing students' drafts and assignments before and after feedback sessions, whereas the current study drew data from an opinion poll, which is self-report data. Although interviews and observations were done with four teachers in the current investigation, they generated qualitative data, which did not influence the quantitative data in the study and they covered a rather limited scope considering the contrast of the sample size between questionnaire respondents and close-up, small-scale interviews. 
Table 1. Kruskal Wallis results for between-group comparisons

\begin{tabular}{|c|c|c|c|c|c|c|}
\hline $\begin{array}{l}\text { What types) of PR are used } \\
\text { in academic writing classes? }\end{array}$ & Group & $\mathrm{N}$ & $\begin{array}{l}\text { Mean } \\
\text { Rank }\end{array}$ & $\begin{array}{r}\text { Chi } \\
\text { square } \\
(\text { df } 2)\end{array}$ & $\begin{array}{l}\text { P(Asympt. } \\
\text { Sig) }\end{array}$ & $\begin{array}{l}\text { Effect size } \\
\text { chi-square/N1 }\end{array}$ \\
\hline \multirow{3}{*}{$\begin{array}{l}\text { T1 } \\
\text { Face-to-face } \\
\text { during class time }\end{array}$} & NSstudent & 124 & 81.09 & 2.320 & .313 & .014 \\
\hline & NNSstudent & 18 & 75.50 & & & \\
\hline & Teachers & 20 & 89.45 & & & \\
\hline \multirow{3}{*}{$\begin{array}{l}\text { T2 Paper-based written } \\
\text { PR during class time }\end{array}$} & NSstudent & 124 & 77.57 & 5.406 & .067 & .034 \\
\hline & NNSstudent & 18 & 91.00 & & & \\
\hline & Teachers & 20 & 97.30 & & & \\
\hline \multirow{3}{*}{$\begin{array}{l}\text { T3 Online } \mathrm{PR} \text { during } \\
\text { class time }\end{array}$} & NSstudent & 124 & 81.92 & .910 & .634 & .005 \\
\hline & NNSstudent & 18 & 78.00 & & & \\
\hline & Teachers & 20 & 82.05 & & & \\
\hline \multirow{3}{*}{$\begin{array}{l}\text { T4 Online PR assigned } \\
\text { as homework }\end{array}$} & NSstudent & 18 & 78.00 & 6.648 & $.036^{*}$ & .041 \\
\hline & NNSstudent & 20 & 90.15 & & & \\
\hline & Teachers & 20 & 80.50 & & & \\
\hline \multirow[t]{3}{*}{ T5 Don't use any PR } & NSstudent & 124 & 81.81 & .617 & .735 & .004 \\
\hline & NNSstudent & 18 & 80.50 & & & \\
\hline & Teachers & 20 & 80.50 & & & \\
\hline
\end{tabular}

Table 2. Post hoc comparisons for significant Kruskal-Wallis tests

\begin{tabular}{|c|c|c|c|c|c|c|}
\hline & $\begin{array}{l}\text { Types with significant } \\
\text { difference b/n groups }\end{array}$ & $\begin{array}{c}\text { Pair-wise } \\
\text { comparisons }\end{array}$ & $\mathrm{N}$ & $\%$ & $\begin{array}{c}\text { Chi-square } \\
\text { (df 1) }\end{array}$ & $\begin{array}{l}\text { Sig. } \\
(p)\end{array}$ \\
\hline \multirow{6}{*}{$\mathrm{T} 4$} & Online PR assigned as & NSstudents vs. & 124 & $3 \%$ & 0.593 & .441 \\
\hline & homework & NNSstudents & 18 & $0 \%$ & & \\
\hline & & NSstudents vs. & 124 & $3 \%$ & 5.172 & $.024^{*}$ \\
\hline & & Teachers & 20 & $15 \%$ & & \\
\hline & & NNSstudents vs. & 18 & $0 \%$ & 2.854 & .059 \\
\hline & & Teachers & 20 & $15 \%$ & & \\
\hline
\end{tabular}

Note: $*=p \leq .05$, but not significant at alpha $=.0166$

There are some reasons why this study yielded different results. First, the difference could be attributed to the fact that the target audience had insufficient experience conducting online PR. When students do not have enough experience in doing online PR, they tend to view it as a useless activity (Kaufman \& Schunn, 2011; Roskams, 1999). Nevertheless, underestimating the value of PR could also happen with F2F peer editing. The second reason could be the context and the special demographic of participants, because none of the studies discussed in the literature was conducted on first-year college students in a bilingual context. Third, as reported by students and instructors (see Table $5 \& 6$ ), students prefer immediate feedback in person to feedback online, a view endorsed by Ho (2015). Other reasons could be credited to the fact that some forms of technology have become distracting for students. By doing F2F peer 
evaluation, students must pay full attention to the task without distractions (Kessler \& Bikowski, 2010; Ho, 2015).

\subsection{Effective Formats of $P R$}

The second research question centered on students and their instructors' perceptions of the most effective PR formats. Both students and teachers yielded corresponding responses. They were provided with five options: face-to-face during class; paper-based during class; online during class; online as homework, and other. For each option, the participants were asked to provide narrative comments justifying their choice. Figure 4 below demonstrates that F2F peer review during class time was believed to be the most effective, followed by paper-based written peer review during class time. According to all participants, online peer review was less effective than $F 2 F$ or paper-based peer reviews. The least effective mode of $\mathrm{PR}$ was online $P R$ during class time. While the informants' preferences to in-person review has echoes in some previous studies (Ho, 2015; Liu \& Sadler, 2003), this finding contradicts the findings of many other studies (Breuch, 2004; Huang, 2016; Saeed et al, 2018; Vorobel \& Kim, 2017).

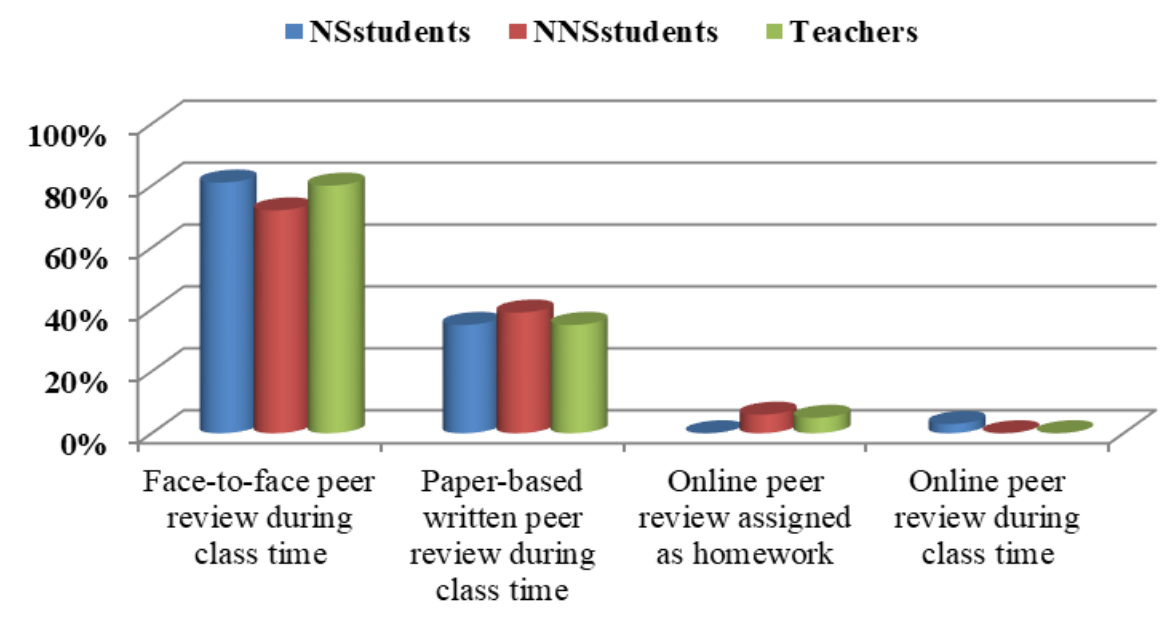

Figure 4. Formats of PR ordered from the most effective mode to the least effective

Excluding the last option, "other", the results of descriptive statistics of the Kruskal Wallis tests (Tables $3 \& 4$ ) reveal only two significant differences between the groups. The first significant difference is on the use of online $P R$ as homework, Chisquare $=6,591, p=.037$, with small effect size $=.04$. The second significant difference is on the option other than the four mentioned above, Chi-square=14.828, $p=.001$, with a medium effect size $=.10$. Post hoc pairwise comparisons were performed for the two significant results in Table 4: online PR assigned as homework and other. 
Table 3. Kruskal-Wallis results for between-group comparisons

\begin{tabular}{|c|c|c|c|c|c|c|c|}
\hline \multicolumn{2}{|c|}{$\begin{array}{l}\text { Which format do you find } \\
\text { the most effective? }\end{array}$} & Group & \multirow{2}{*}{$\frac{\mathrm{N}}{124}$} & \multirow{2}{*}{$\begin{array}{c}\text { Mean } \\
\text { Rank }\end{array}$} & \multirow{2}{*}{$\begin{array}{r}\begin{array}{c}\text { Chi- } \\
\text { square } \\
(\mathrm{df} 2)\end{array} \\
.685\end{array}$} & \multirow{2}{*}{$\begin{array}{c}\mathrm{p} \\
\text { (Asympt. } \\
\text { Sig) } \\
.710\end{array}$} & \multirow{2}{*}{$\begin{array}{c}\begin{array}{c}\text { Effect size } \\
\text { chi- }\end{array} \\
\text { square/N-1 } \\
.004\end{array}$} \\
\hline $\mathrm{T} 1$ & Face-to-face PR & NSstudent & & & & & \\
\hline & during class time & NNSstudent & 18 & 75.50 & & & \\
\hline & & Teachers & 20 & 81.80 & & & \\
\hline \multirow[t]{3}{*}{$\mathrm{T} 2$} & Paper-based & NSstudent & 124 & 81.09 & .122 & .941 & .002 \\
\hline & written PR during & NNSstudent & 18 & 84.50 & & & \\
\hline & class time & Teachers & 20 & 81.35 & & & \\
\hline \multirow[t]{3}{*}{ T3 } & Online PR during & NSstudent & 124 & 82.11 & 1.249 & .536 & .02 \\
\hline & class time & NNSstudent & 18 & 79.50 & & & \\
\hline & & Teachers & 20 & 79.50 & & & \\
\hline \multirow[t]{3}{*}{$\mathrm{T} 4$} & Online PR assigned & NSstudent & 124 & 80.50 & 6.591 & $.037^{*}$ & .04 \\
\hline & as homework & NNSstudent & 18 & 85.00 & & & \\
\hline & & Teachers & 20 & 84.55 & & & \\
\hline \multirow[t]{3}{*}{$\mathrm{T} 5$} & Other & NSstudent & 124 & 80.15 & 14.828 & $.001^{* *}$ & .10 \\
\hline & & NNSstudent & 18 & 79.50 & & & \\
\hline & & Teachers & 20 & 91.65 & & & \\
\hline
\end{tabular}

Note: ${ }^{*}=$ significant at $p<.05 ; * *=$ significant at $\mathrm{p} \leq .001$

Among the three groups, there are four significant differences. The first one on the use of online PR as homework is between NS and NNS students, Chi-square $=6.889$; $p=.009$. The second is between NS students and teachers, Chi-square $=6.200, p=.013$. A significant difference between NNS students and teachers did not exist. In using other forms of PR, there was a significant difference between teachers and students (NS and NNS). There was not a significant difference between students. This shows that teachers are more aware of more formats of PR than their students are.

Table 4. Post hoc comparisons for significant Kruskal-Wallis tests

\begin{tabular}{|c|c|c|c|c|c|}
\hline $\begin{array}{l}\text { Formats with significant } \\
\text { difference b/n groups }\end{array}$ & $\begin{array}{r}\text { Pair-wise } \\
\text { comparisons }\end{array}$ & $\mathrm{N}$ & $\%$ & $\begin{array}{c}\text { Chi-square } \\
\text { (df } 1)\end{array}$ & $\begin{array}{l}\text { Sig. } \\
\text { (p) }\end{array}$ \\
\hline \multirow{4}{*}{$\begin{array}{l}\text { F4 Online PR assigned as } \\
\text { homework }\end{array}$} & NSstudents vs. & 124 & $0 \%$ & 6.889 & $.009 *$ \\
\hline & NNSstudents & 18 & $6 \%$ & & \\
\hline & NSstudents vs. & 124 & $0 \%$ & 6.200 & $.013^{*}$ \\
\hline & Teachers & 20 & $5 \%$ & & \\
\hline \multirow{8}{*}{ F6 Other } & NNSstudents vs. & 18 & $6 \%$ & .006 & .940 \\
\hline & Teachers & 20 & $5 \%$ & & \\
\hline & NSstudents vs. & 124 & $1 \%$ & .145 & .703 \\
\hline & NNSstudents & 18 & $0 \%$ & & \\
\hline & NSstudents vs. & 124 & $1 \%$ & 12.758 & $.000 * *$ \\
\hline & & 20 & $15 \%$ & & \\
\hline & NNSstudents vs. & 18 & $0 \%$ & 12.854 & $.000 * *$ \\
\hline & Teachers & 20 & $15 \%$ & & \\
\hline
\end{tabular}

Note: Significance $* *=p \leq .001 ;$ Sig $*=p \leq .0166$

Even though there were significant between-group differences on two of the five survey options, the mean values clearly show the formats deemed most and least effective. Taken together, the quantitative data show an agreement among all groups 
that face-to-face PR during class time is the most effective tool of PR. It is not surprising if they have not had enough experience with online PR.

When asked about the reasons why they think this format is the most effective one, 90 students (63\%) and 14 instructors (70\%) provided explanations. The data was coded through content analysis into themes and quotes were selected to illustrate each theme. Tables 5 and 6 below summarize the main themes and samples of illustrations. Generally, both students and teachers provided similar reasons for selecting face-toface PR during class being the most effective mode. Both groups agreed that F2F peer editing encourages discussion, develops communication skills, and provides immediate feedback. Students believe that this mode is more personal and yields better outcomes, whereas the teachers think that this approach encourages collaborative learning and allows for instructors' intervention. As Table 5 shows, 33\% of the students (out of $63 \%$ ) believe that this mode is effective because it encourages interaction. $26 \%$ of the students reported that this approach yields better outcome, $23 \%$ prefer this approach because it provides them with immediate feedback, and $15 \%$ perceive this method as an effective way to develop communication skills. Finally, $7 \%$ of the respondents find it more personal and thus more effective.

As for instructors, 14 out of 20 (70\%) provided reasons why they think that F2F peer editing is effective. As indicated in Table 6, the majority of the instructors (36\%) believe F2F peer work encourages discussion and facilitates interaction. $22 \%$ of the instructors reported that this mode of $\mathrm{PR}$ develops communicational skills and promotes trust and honesty among students. In addition, $21 \%$ stated that this format of PR provides immediate feedback. Last but also significant, $14 \%$ of the instructors believe that it encourages collaborative learning and gives room for teacher intervention to facilitate and assess learner's peer work.

Table 5. Students' responses to why face-to-face peer review during class time is effective

\begin{tabular}{|c|c|c|}
\hline Themes & Illustrations & N (\%) \\
\hline Encourages discussion & $\begin{array}{l}\text { NS Student: "Sometimes when they talk to me face to face it helps me } \\
\text { understand more. It also helps by talking about whatever they may } \\
\text { have missed on the paper." } \\
\text { NNS Student: "It give you the opportunity to ask questions } \\
\text { about something you don't understand at the moment." }\end{array}$ & $33 \%$ \\
\hline Yields better outcomes & $\begin{array}{l}\text { NS Student: "It's better to discuss the paper face to face } \\
\text { because you can explain things more." }\end{array}$ & $26 \%$ \\
\hline Provides immediate feedback & $\begin{array}{l}\text { NS Student: "I like the face-to-face PR during class because I can } \\
\text { immediate feedback from the person." }\end{array}$ & $23 \%$ \\
\hline Develops communication & NS Student: "Face to Face helps communication skills." & \\
\hline skills & & $15 \%$ \\
\hline More personal & NNS Student "Because it's more personal." & $7 \%$ \\
\hline
\end{tabular}


Table 6. Instructors' responses to why face-to-face peer review during class time is effective

\begin{tabular}{|c|c|c|}
\hline Themes & Illustrations & N (\%) \\
\hline Encourages discussion & $\begin{array}{l}\text { "With F2F peer review I feel better able to facilitate a } \\
\text { conversation around the works being considered." }\end{array}$ & $36 \%$ \\
\hline $\begin{array}{l}\text { Develops communication skills as } \\
\text { well as trust and honesty among } \\
\text { students }\end{array}$ & $\begin{array}{l}\text { Having students actually interact with each other as well as } \\
\text { their writing is helpful in creating an environment of trust and } \\
\text { honesty among students." }\end{array}$ & $22 \%$ \\
\hline Provides immediate feedback & $\begin{array}{l}\text { "I think that they can address any issues that come up more } \\
\text { flexibly and immediately by talking rather than writing." }\end{array}$ & $21 \%$ \\
\hline Encourages collaborative learning & $\begin{array}{l}\text { "Having face to face interaction allows collaborative learning } \\
\text { as the give and take advice." }\end{array}$ & $14 \%$ \\
\hline Allows for instructors' intervention & $\begin{array}{l}\text { "I think it essential that I am there to facilitate peer reviews. I } \\
\text { can often jump start reviews that are stalling or redirect } \\
\text { reviews that are getting either off track or antagonistic." }\end{array}$ & $14 \%$ \\
\hline
\end{tabular}

For the second format of PR (paper-based written PR during class time), 31 students (22\%) explained why they think this mode is effective. The majority of them (61\%) believe that the effectiveness of this format comes from the fact they have it written down so they can refer to it later on. $13 \%$ thought that this format yields better results, $16 \%$ found it effective in finding mistakes, and $10 \%$ preferred this mode because they feel it is less awkward, and therefore less intimidating. Table 7 summarizes these themes with illustrations from participants' narrative comments.

Instructors provided similar reasons. Only five of them (25\%) elaborated on their reasons for choosing this option. As elicited from the open-ended question in survey, $80 \%$ believe that paper-based $P R$ is effective because students can refer to later on "This way the students will have some notes to refer to outside our class." Twenty percent reported that paper-based is less intimidating "It is not as intimidating or distracting as face-to-face peer review." Teachers who chose "Other" (total=2) suggested that students should be sitting side by side instead of face to face because it is "less intimidating for many students. It is hard to look at someone when they are reading your paper! "One instructor recommends using a variety of modes to be able to accommodate all learners.

Table 7. Responses to why paper-based written PR during class time is effective

\begin{tabular}{ll}
\hline \multicolumn{1}{c}{ Themes } & \multicolumn{1}{c}{ Illustrations } \\
\hline Written records to refer to & "I also like paper-based written peer reviews because when I go \\
& $\begin{array}{l}\text { back home I can look through the notes that the other person has } \\
\text { made on my rough draft." }\end{array}$ \\
Yields better outcomes & "good way to improve my work" \\
Easy to find mistakes & "I can find my mistakes easily." \\
Less awkward and less & "Less awkward." \\
intimidating & \\
\hline
\end{tabular}


On the main, the findings of the current study bring to light differences in the way students and their instructors tout PR formats and types, some of which diverge from previous studies. This particular study uncovered students' completion of PR in class and online, yet F2F review was more common and effective than other review modes. Putting the issue in the body of literature, several researchers investigated how different PR modes could be effective. Liu and Sadler (2003) maintained that teachers could employ a variety of modes depending on the objectives and the contexts of their classes. Some researchers (e.g. Desirable, 2015; Huang, 2016; Lin \& Yang, 2011; Vorobel \& Kim, 2017) found that online tools provide a better environment for peer editing. For others, the traditional setting is less distracting and thus more effective than an online setting (e.g. Kessler \& Bukowski, 2010; Ho, 2015). At least when students had less experience with online PR than with F2F peer review, it can be said that peer feedback offered in person is better for communication while online PR is better for producing more comments (Liu \& Sadler, 2003). Moreover, the study aligns with Ahmed (2020) in that such classroom-based research "raise awareness of an undercurrent present beneath the surface process that is usually ignored or not even perceived by writing instructors" (p. 15).

\section{Conclusion}

Brining in evidence from a mid-southern US university, this study unveiled the frequencies of using PR showing how NS and NNS students and their instructors perceive its viability in academic writing classes. The study compared the technologybased PR (online) with the traditional form that takes place in the classroom. The results of the first research question, contrary to expectations, revealed that online PR adds less significant value to the F2F peer assessment. By taking this result into practice, writing instructors, teacher educators, practitioners, and students may invest in classroom-based peer editing and, at the same time, are encouraged to opt for online PR. Teacher training programs should include peer editing with its various types and formats, including materials that foster effective PR and student-centered interactions. The study as it stands is not devoid of certain limitations that should be considered when interpreting the results and/or when designing future studies. Employing more instructors could have enriched the investigation. Future research may also investigate participants who have sufficient experience in all types of $P R$ and focus on how students perform the review in different online platforms that facilitate the task of peer evaluation and promote interaction. Last, but certainly not least, as the online review is text-based and F2F review is both text-based and speech-based, the corpus of review (either written or coded speech) is another venue for further undertaking. These limitations provide room for future projects that may draw on the findings the present study have brought to the foreground.

\section{The Research and Publication Ethics Statement}


The Ethics Committee/Board approval for this study was obtained from the University of Memphis IRB Committee (Approval No: PRO-FY2017-261). Date of the approval, $01 / 02 / 2017$. No ethical considerations were violated in this study.

\section{The Conflict of Interest Statement}

In line with the statement of Committee on Publication Ethics (COPE), we hereby declare that we had no conflicting interests regarding any parties of this study. This research study is not funded by any institution.

\section{References}

Ahmed, R. (2020) Peer review in academic writing: Different perspectives from instructors and students. TESOL J., 00:e537. https://doi.org/10.1002/tesj.537

Berg, E. C. (1999). The effects of trained peer response on ESL students' revision types and writing quality. Journal of Second Language Writing, 8(3), 215-241.

Bradley, L. (2014). Peer reviewing in an intercultural wiki environment: Student interaction and reflections. Computers and Composition, 14, 80-95.

Brammer, C., \& Rees, M. (2007). Peer review from the students' perspective: Invaluable or valid? Composition Studies, 35(2), 71.

Breuch, L.K. (2004). Virtual peer review: Teaching and learning about writing in online environments. New York: State University of New York Press.

Caulk, N. (1994). Comparing teacher and student responses to written work. TESOL Quarterly, 28(1), 181-188.

Chen, K. (2012). Blog-based peer reviewing in EFL writing classrooms for Chinese speakers. Computers and Composition, 29, 280-291.

Daweli, T. W. (2018). Engaging Saudi EFL students in online peer review in a Saudi university context. Arab World English Journal, 9(4), 270-280. DOI: https://dx.doi.org/10.24093/awej/vol9no4.20

Desirable, M. (2015). Social media and peer feedback: What do students really think about using Wiki and Facebook as platforms for peer feedback? Active Learning in Higher Education. https://doi.org/10.1177/1469787415589530.

DiCamilla, F., J. \& Anton, M. (1997). Repetition in the collaborative discourse of L2 learners: A Vygotsky perspective. Canadian Modern Language Review, 53(4), 609-633.

Field, A. (2009). Discovering statistics using SPSS (3 ${ }^{\text {rd }}$ edition). Sage Publications Ltd.

Hansen, J. G., \& Liu, J. (2005). Guiding principles for effective peer response. ELT journal, 59(1), 31-38.

Ho, M. C. (2015). The effects of face-to-face and computer-mediated peer review on EFL writers' comments and revisions. Australasian Journal of Educational Technology, 31(1).

Hojeij, Z. \& Baroudi, S. (2018). Student perceptions on peer feedback training using a blended method: A UAE case. Issues in Educational Research, 28(3), 655- 678. http://www.iier.org.au/iier28/hojeij.pdf

Hu, G. (2005). Using peer review with Chinese ESL student writers. Language Teaching Research, 9(3), 321-342.

Huang, J. (2016). Contribution of online peer review to effectiveness of EFL writing. American Journal of Educational Research, 4(11), 811-816. Doi: 10.12691/education-4-11-6 
Kaufman, J. H., \& Schunn, C. D. (2011). Students' perceptions about peer assessment for writing: Their origin and impact on revision work. Instructional Science, 39(3), 387-406.

Kessler, G. (2018). Technology and the future of language teaching. Foreign language annals, 51(1), 205-218.

Kessler, G., \& Bukowski, D. (2010). Developing collaborative autonomous learning abilities in computer mediated language learning: Attention to meaning among students in wiki space. Computer Assisted Language Learning, 23(1), 41-58.

Lei, X. (2008). Exploring a sociocultural approach to writing strategy research: Mediated actions in writing activities. Journal of Second Language Writing, 17(4), 217-236.

Li, J. \& Li, M. (2018). Turnitin and peer review in ESL academic writing classrooms. Language Learning \& Technology, 22(1), 27-41. https://dx.doi.org/10125/44576

Lin, W. C., \& Yang, S. C. (2011). Exploring students' perceptions of integrating wiki technology and peer feedback into English writing courses. English Teaching, 10(2), 88.

Liu, J., \& Sadler, R. W. (2003). The effect and affect of peer review in electronic versus traditional modes on L2 writing. Journal of English for academic Purposes, 2(3), 193- 227.

López-Pellisa, T., Rotger, N. \& Rodríguez-Gallego, F. (2020). Collaborative writing at work:

Peer feedback in a blended learning environment. Education and Information Technologies. https://doi.org/10.1007/s10639-020-10312-2

Mick, C. \& Middlebrook, G. (2015). Asynchronous and synchronous modalities. In Beth L. Hewett \& Kevin Eric DePew, (Eds.), Foundational practices of online writing instruction (pp.129-148).

Hoomanfard, M. \& Rahimi, M. (2018). A comparative study of the efficacy of teacher and peer online written corrective feedback on second language learners' writing improvement. Scientific Journal of Language Research, 11(33), http://jlr.alzahra.ac.ir

Moloudi, M. (2011). Online and face-to-face peer review: Measures of implementation in ESL writing Classes. Asian EFL Journal, 4-23.

Razı, S. (2016). Open and anonymous peer review in a digital online environment compared in academic writing context. In C. Goria, O. Speicher, \& S. Stollhans (Eds), Innovative language teaching and learning at university: Enhancing participation and collaboration (pp. 49-56). Dublin: Researchpublishing.net. http://dx.doi.org/10.14705/rpnet.2016.000404

Roskams, T. (1999). Chinese EFL students' attitudes to peer feedback and peer assessment in anextended pairwork setting. RELC Journal, 30(1), 79-123. doi: $\mathbf{1 0 . 1 1 7 7 / 0 0 3 3 6 8 8 2 9 9 0 3 0 0 0 1 0 5}$

Saeed, M., Ghazali, K. \& Aljaberi, M. (2018). A review of previous studies on ESL/EFL learners' interactional feedback exchanges in face-to-face and computer-assisted peer review of writing. International Journal of Educational Technology in Higher Education, 15, 6. DOI 10.1186/s41239-017-0084-8

Storch, N. (2005). Collaborative writing: Product, process, and students' reflections. Journal of Second Language Writing, 14(3), 153-173.

Vorobel, O., \& Kim, D. (2017). Adolescent ELLs' collaborative writing practices in face-to-face and online contexts: From perceptions to action. System, 65, 78-89.

Vygotsky, L. (1978). Mind in society. Cambridge, MA: Harvard University Press.

\section{Appendix A. Students' Survey}


1 Name (optional)

2 How old are you?

3 Gender

Male

Female

Other

4 Your first language is....

English

Other

5 How often does your teacher use peer reviews in your academic writing class?

a) With all major assignments

b) With more than half of the major writing assignments

c) With less than half of the major writing assignments

d) Never

6 What type(s) of peer review does your teacher use in your academic writing class? (Select all that apply)

a) Face-to-face peer review during class time

b) Paper-based written peer review during class time

c) Online peer review during class time

d) Online peer review assigned as homework

e) He doesn't use any peer review

f) Other

7 Which format do you find the most effective?

a) Face-to-face peer review during class time

b) Paper-based written peer review during class time

c) Online peer review during class time

d) Online peer review assigned as homework 
e) I don't use any peer review

f) Other

7.a Explain why

7.b Explain why

7.c Explain why

7.d Explain why

7.e Explain why

7.f Explain why

8 Does your teacher provide you with specific guidelines and questions that you need to follow during the peer review?

Yes

No

9 Which would you prefer?

To follow a specific questionnaire when doing peer review

To be able to express what you think without following a questionnaire

9.a Explain why

9.b Explain why 
10 Which of the following aspects of writing do you focus on when doing peer reviews? Select all that apply.

Grammar range and accuracy

Sentence Structure

Vocabulary range and appropriateness

Spelling and Punctuation

Thesis Statement

Purpose

Overall Organization

Paragraph structure and organization

Evidence/Examples

Overall Content and its relevance to the task/prompt

Coherence of ideas

Citations and references

MLA Format

Other (list all other aspects not mentioned above)

11 Does your teacher provide feedback on the quality of your reviews?

Yes

No

11.a If yes, describe how your teacher informs you about the quality of your reviews?

12 Based on your experience, how helpful is peer review for improving your academic writing?

Very helpful

Helpful

Somewhat helpful

Unhelpful

Very unhelpful

Have never received peer review 
13 How comfortable are you peer reviewing your classmate's papers?

Very comfortable

Mostly comfortable

Somewhat comfortable

Mostly uncomfortable

Not comfortable at all

14 How confident are you in reviewing your classmates' papers?

a) I am confident that I always provide correct and useful feedback.

b) I think that my feedback is mostly correct and useful.

c) I sometimes have doubts whether I am providing good feedback.

d) I often doubt whether my feedback is correct or not.

e) I do not know whether my feedback is correct or not.

14.a Explain your response above

14.b Explain your response above

14.c Explain your response above

14.d Explain your response above

14.e Explain your response above

15 How comfortable are you having your paper reviewed by other students?

a) Very comfortable

b) Mostly comfortable

c) Somewhat comfortable

d) Mostly uncomfortable 
e) Not comfortable at all

15.a Explain why

15.b Explain why

15.c Explain why

15.d Explain why

15.e Explain why

16 If you could choose to do or not to do peer reviews in your writing class, which would you choose?

a) never use peer reviews in my writing class

b) use peer reviews only with one or two major assignments

c) use peer reviews with all major assignments

16.a Explain why

16.b Explain why

16.c Explain why

17 What do you think are the problems of peer review? (Check all that apply)

a) Peer review takes too much time

b) I am not confident enough to give feedback to my peers

c) My peers don't value my feedback. 
d) I tend to avoid writing any critical comments.

e) I am restricted to the worksheet giving by the instructor.

f) The groups are not chosen properly.

g) The furniture and the space of the class do not allow us to perform peer review sessions.

h) I don't value peer review because I do not receive any credit for it.

i) No problems at all.

j) Other (list all other problems not mentioned above)

18 If you listed any problems above, what solutions do you propose? (Write N/A if you did not select any).

19 Which of the following formats of peer review would you like your instructor to use?

a) Oral discussions in pairs or small groups during class

b) Paper-based written reviews during class

c) Online written reviews during class

d) Online written reviews done at home

e) Other

19.a Explain why

19.b Explain why

19.c Explain why

19.d Explain why

19.e Explain why 
20 Which online forms of peer review would you like your instructor to use?
a) Structured questionnaires
b) Informal blogs
c) Other

21 Who do you think benefits more from peer reviews?

a) The person providing the review

b) The person receiving the review

21.a Explain why

21.b Explain why

22

Finish

the

following

statement.

In order to make peer reviews an effective tool for teaching academic writing skills, it is important to

\section{Appendix B. Instructors' Survey}

1. Name (optional)

2. How old are you

3. Gender

Male

Female

Other 
4. Your first language is....

English

Other

5. Which of the following describe your purpose of incorporating peer reviews in your academic writing class? Choose all that apply.

a) To provide feedback to the student writer

b) To raise the reviewing student's awareness of important aspects of writing

c) To assess student's ability to provide feedback

d) Other

6. How often do you use peer review in your academic writing classes?

a) With all major assignments

b) With more than half of the major writing assignments

c) With less than half of the major writing assignments

d) Never

7. What type(s) of peer review do you use in your academic writing classes? (Select all that apply)

a) Face-to-face peer review during class time

b) Paper-based written peer review during class time

c) Online peer review during class time

d) Online peer review assigned as homework

e) I don't use any peer review

f) Other

8. Which format do you find the most effective?

a) Face-to-face peer review during class time

b) Paper-based written peer review during class time

c) Online peer review during class time

d) Online peer review assigned as homework

e) I don't use any peer review

f) Other

8.a Explain why 
8.b Explain why

8.c Explain why

8.d Explain why

8.e Explain why

8.f Explain why

9. Do you teach your students how to do peer reviews?

Yes

No

9.a If yes, explain what you do, giving specific examples.

9.b If no, explain why

10. When you ask students to do peer reviews, do you provide them with specific guidelines?

Yes

No

10.a If yes, explain what kind of guidelines you provide? In what form? Are these guidelines based on the writing rubric that you use to assess students' writing? 
10.b If no, explain why you prefer unstructured peer reviews.

11. Which of the following aspects of writing do you direct your students to focus on when doing peer reviews? Select all that apply or none if you use unstructured forms of peer review.

Grammar range and accuracy

Sentence Structure

Vocabulary range and appropriateness

Spelling and Punctuation

Thesis Statement

Purpose

Overall Organization

Paragraph structure and organization

Evidence/Examples

Overall Content and its relevance to the task/prompt

Coherence of ideas

Citations and references

MLA Format

Other (list all other aspects not mentioned above)

12. Do you examine the peer review feedback before submitting it to the recipient students?

Yes

No

12.a Explain why

12.b Explain why 
13 Do you provide feedback on the quality of the peer review to the reviewers? Yes

No

13.a Explain why

13.b Explain why

14. Based on your experience, how helpful is peer review for improving students' academic writing?

Very helpful

Helpful

Somewhat helpful

Unhelpful

Very unhelpful

Have never used peer review

15. If you could choose to do or not to do peer reviews in your writing class, which would you choose?

a) never use peer reviews in my writing class

b) use peer reviews only with one or two major assignments

c) use peer reviews with all major assignments

15.a Explain why

15.b Explain why

15.c Explain why

16. Some of the problems you encounter when you use peer review are (check all that apply)

a) Peer review takes too much time 
b) Students lack confidence in giving feedback

c) Students don't value their classmates' feedback.

d) Students tend to avoid writing any critical comments.

e) You find it difficult to interfere and provide comments during the process of peer review.

f) Institutional constraints

g) It is hard to organize the students into groups.

h) The furniture and the space of the class do not allow you to conduct peer review sessions.

i) Students don't value it because they are not graded on it.

j) No problems at all/prompt.

Other (list all other problems not mentioned above)

17. If you listed any problems above, what solutions do you propose? (Write N/A if you didn't select any).
18.
Finish
the
following
sentence.

In order to make peer reviews an effective tool for teaching academic writing skills, it is important to

\section{Appendix C. Classroom Observation Sheet}

Background information

Instructor: Course:

Time/Date: Number of students:

Preparation:

How does the instructor prepare students for the peer review workshop?

Were students trained to do peer review?

How are students divided into groups?

Does the instructor provide a peer review worksheet? Is the peer review session structured or unstructured?

Did you observe any problems from the part of students, teachers, and/or the classroom setting? 
During peer review:

How many students in each group?

How do students get started?

How

long does it take to review each paper?

Is the peer review anonymous?

Do students discuss their feedback?

What

is the role of the instructor?

Evaluation:

How do students receive feedback from their classmates?

the instructor evaluate the quality of peer review?

you think the students are interested in the lesson? Explain.

\section{Appendix D. Interview Questions}

What is your educational background?

How long have you been teaching? How long have you been using peer review?

What is a peer review session?

How well prepared are you facilitating peer review sessions? What background do you have?

Why do you choose to use peer review sessions in your writing classes? Why do you believe they are beneficial for your students' writing? 
Do you train your students on peer review? If so, how?

Do you model peer review for them?

Was the modelling training effective?

What else do you consider in preparation of peer review sessions and in training?

Does the level of students' proficiency matter for peer review sessions? Why? How?

What can influence your decision to apply peer review sessions in your class?

How many L2 learners in yours class? Do you do anything different with them?

How do you deal with ESL learners?

What problems do you encounter? (Logistical constraints, student resistance, lack of expertise on the part of the students, issues in evaluating the quality of the peer review).

How do you solve these problems?

Have you changed the way you do peer review? If so, are the new methods more effective?

Do you give feedback on their reviews?

What should I have asked you that I didn't think to ask?

\section{Copyrights}

Copyright for this article is retained by the author(s), with first publication rights granted to the Journal. This is an open-access article distributed under the terms and conditions of the Creative Commons Attribution license (CC BY-NC-ND) (http://creativecommons.org/licenses/by-nc-nd/4.0/). 